\title{
The Influence of Thermal History on the Microstructure and Mechanical Proper- ties of AlSi8Cu2Fe Alloy
}

Jan Šerák, Dalibor Vojtěch, Cyril Šimon

Univeristy of Chemistry and Technology Prague, Department of Metals and Corrosion Engineering, Technicka 5, 16628 Prague 6, Czech Republic, E-mail: serakj@vscht.cz

In this work the influence of cyclic thermal history on the microstructure and mechanical properties of AlSi8Cu2Fe alloy was studied. The commercial aluminum alloy was subjected to a special heat treatment during which the alloy repeatedly changed from a liquid to a semi-solid state. During this process, samples were taken, and the castings were subjected to another study. Gradual changes in the microstructure, chemical composition of the alloy, hardness and mechanical properties under pressure at normal temperatures have been documented. The content of alloying elements, especially magnesium, decreased significantly, the proportion of casting defects increased, especially hydrogen bubbles, microshrinkage and oxide inclusions in the alloy, with the increasing number of cycles. These changes also led to a decrease in the mechanical properties of the alloy. A series of samples without cyclic heat loading was also prepared for comparison.

Keywords: Aluminum Alloys, Microstructure, Mechanical Properties, Heat Treatment, Gravity Casting

\section{Introduction}

In this work, the influence of the specific thermal history of the commercial AlSi8Cu2Fe alloy (ČSN 42 4339) on its microstructure and selected mechanical properties was studied. The melt was exposed to longterm cyclic thermal exposure, during which the alloy was completely in a liquid state and after a drop in temperature in the partly crystallized state (between liquidus and solidus temperatures). This cycle simulates the conditions that may occur in some technological processes during foundry production $[1,2]$. So far, no one scientific work has dealt with this topic in detail within the systematic study.

During long-term exposure of the melt in the presence of the atmosphere, the effects of oxidation of aluminum and other elements with a high affinity to oxygen may gradually begin to manifest. This leads, on the one hand, to the formation of oxide phases which can partly float to the surface of the melt and partly form large membranes or inclusions inside the melt. Oxidation processes can further lead to a significant decrease in the content of some alloying elements in the melt. The oxide phases in the melt generally increase the susceptibility of the melt to hydrogen absorption. The degree of oxidation and gasification can then be further increased by the effects of melt mixing, which can lead to a systematic failure of the oxide layer on the surface of the melt, which, if compact, slows down further oxidation of the melt. All these factors can then lead to a significant decrease in the mechanical and physical properties of the castings in particular [3-5]. Temperature fluctuations in the melt together with turbulences in the flowing melt [1] were the cause of foundry defects in the channel leaving the holding furnace, see Fig.1.

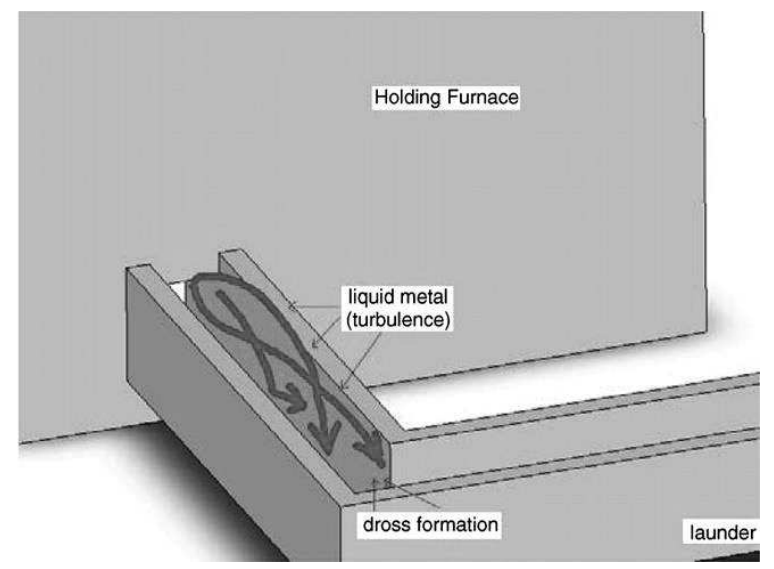

Fig. 1 Turbulence and dross formation in the melt at the outlet of holding furnace [1]

Because commercial alloys usually contain many additive and accompanying elements, several interdependent simultaneous chemical reactions can take place under the stated conditions. Due to the gradual changes taking place in the melt, the conditions of thermodynamic equilibrium cannot be assumed. Empirical relationships must then be used to predict the effects of gradual changes in the melt on the properties of the castings. Even more complicated is the situation if the temperature fluctuations in the alloy also include cooling to a temperature range where the melt and the solid phase coexist, and heterogeneous crystallization nuclei can be affected [6-9]. 
In this work, the influence of special cyclic heat treatment on the microstructure and selected mechanical properties of commercial AlSi8Cu2Fe alloy ( $\breve{C S N}$ 42 4339) was studied. AlSi8Cu2Fe is a hypoeutectic aluminum alloy containing silicon, copper and other alloying elements used for general purposes and also for die casting. This alloy is often used to produce dynamically stressed and complex castings of larger sizes, such as automotive gearboxes or engine blocks. This alloy has very good casting properties, especially very high castability. Due to the very fine microstructure of die cast alloy, it does not undergo otherwise usual heat treatment, which would not lead to a significant increase in mechanical properties as in most other aluminum alloys. This alloy is an example of an "ecologic alloy" which, when processed by die casting technology, may contain significantly higher amounts of some elements than conventional gravity cast alloys. A typical example is iron, which is in this alloy present in the form of extremely fine intermediary phases, which do not disturb the structural homogeneity of the alloy under rapid solidification conditions during die casting to such an extent as in the case of gravity casting technology [8]. Iron is a typical element which is is practically always present in the recycled aluminum alloys. As a result of efforts to maximize recycling, aluminum alloys may also contain several other elements which, even in small quantities, can significantly influence the properties of aluminum alloys.

The influence of accompanying and alloying elements on the properties of AlSi8Cu2Fe alloy castings is relatively well documented [7-14], as well as the possibilities of its heat treatment [15-18].

Although the parameters of casting equipment in modern foundry technologies are usually very well set, sometimes there may be a situation where temperature fluctuations are adversely affected during the transport of the melt from the holding furnace to the mold, long-term maintenance of large amounts of alloy in the molten state, or in continuous furnaces, where both the chemical composition of the melt and the temperature conditions change.

To ensure the production of castings with longterm reproducible properties, it is necessary to know the effects of fluctuations in technological operations during foundry production on the properties of castings. This work also deals with this problem.

\section{Experiment}

Commercial AlSi8Cu2Fe alloy (ČSN 42 4339) with chemical composition shown in the Tab. 1 was used in this experiment.

Tab. 1 Chemical composition of base commercial AlSi8Cu2Fe alloy (ČSN 424339 ), wt\%

\begin{tabular}{|c|c|c|c|c|c|c|c|c|c|c|c|}
\hline $\mathbf{S i}$ & $\mathbf{C u}$ & $\mathbf{M n}$ & $\mathbf{F e}$ & $\mathbf{M g}$ & $\mathbf{N i}$ & $\mathbf{S n}$ & $\mathbf{Z n}$ & $\mathbf{T i}$ & $\mathbf{P b}$ & $\mathbf{C r}$ & $\mathbf{A l}$ \\
\hline 11.5 & 2.39 & 0.19 & 0.66 & 0.48 & 0.12 & 0.03 & 0.91 & 0.05 & 0.12 & 0.04 & bal. \\
\hline
\end{tabular}

The cooling curve of the alloy was measured to determine the crystallization interval. The results are in Tab. 2.

Tab. 2 Characteristic temperatures of AlSi8Cu2Fe alloy (ČSN 424339 ) obtained by thermal analysis, ${ }^{\circ} \mathrm{C}$

\begin{tabular}{|c|c|c|}
\hline $\begin{array}{c}\text { Liquidus } \\
\text { temperature }\end{array}$ & $\begin{array}{c}\text { Start crystalliza- } \\
\text { tion of eutectic } \\
\text { phase }\end{array}$ & $\begin{array}{c}\text { Solidus tem- } \\
\text { perature }\end{array}$ \\
\hline 582 & 566 & 497 \\
\hline
\end{tabular}

The cyclic thermal exposure was performed in a graphite crucible placed in an electric resistance furnace at a temperature of $750^{\circ} \mathrm{C}$ without the use of a protective atmosphere. After the cycle heat exposure, the melt was homogenized by hand mixing using a graphite rod. The temperature of the alloy was controlled by a K-type jacketed thermocouple. The melt was poured into a massive brass mold (cooling rate approx. $10 \mathrm{Ks}^{-1}$ ). During the experiments, the laboratory temperature ranged from 22 to $25^{\circ} \mathrm{C}$ and the relative humidity from 50 to $55 \%$.
Cylindrical samples with a diameter of $20 \mathrm{~mm}$ were used for all experiments. During the exposure, samples were taken after several cycles to study the microstructure, measure the hardness and perform a uniaxial pressure test.

The cyclic exposure of the alloy was based on a melt heated to $750^{\circ} \mathrm{C}$. This was followed by removal from the furnace, hand mixing with a graphite rod and free cooling for 15 minutes. The crucible with the alloy was then inserted into a furnace heated to $750^{\circ} \mathrm{C}$ for 1 hour, see Fig.2. Alloy samples were taken after 1, 2, 4, $8,16,32,64$ and 100 cycles.

The same alloy was also melted for 100 hours in an electric resistence furnace at $750^{\circ} \mathrm{C}$ without cyclic thermal exposure for comparison. Only at defined time exposures the comparative samples cast in the same massive brass mold were taken. Sampling times were after 8, 16, 32, 64 and 100 hours of exposure. The ratio of the area of the melt communicating with the surrounding atmosphere to its volume did not change significantly during the experiment, even in the case of the comparative series without cyclic thermal exposure, as can be seen from Tab. 3. 


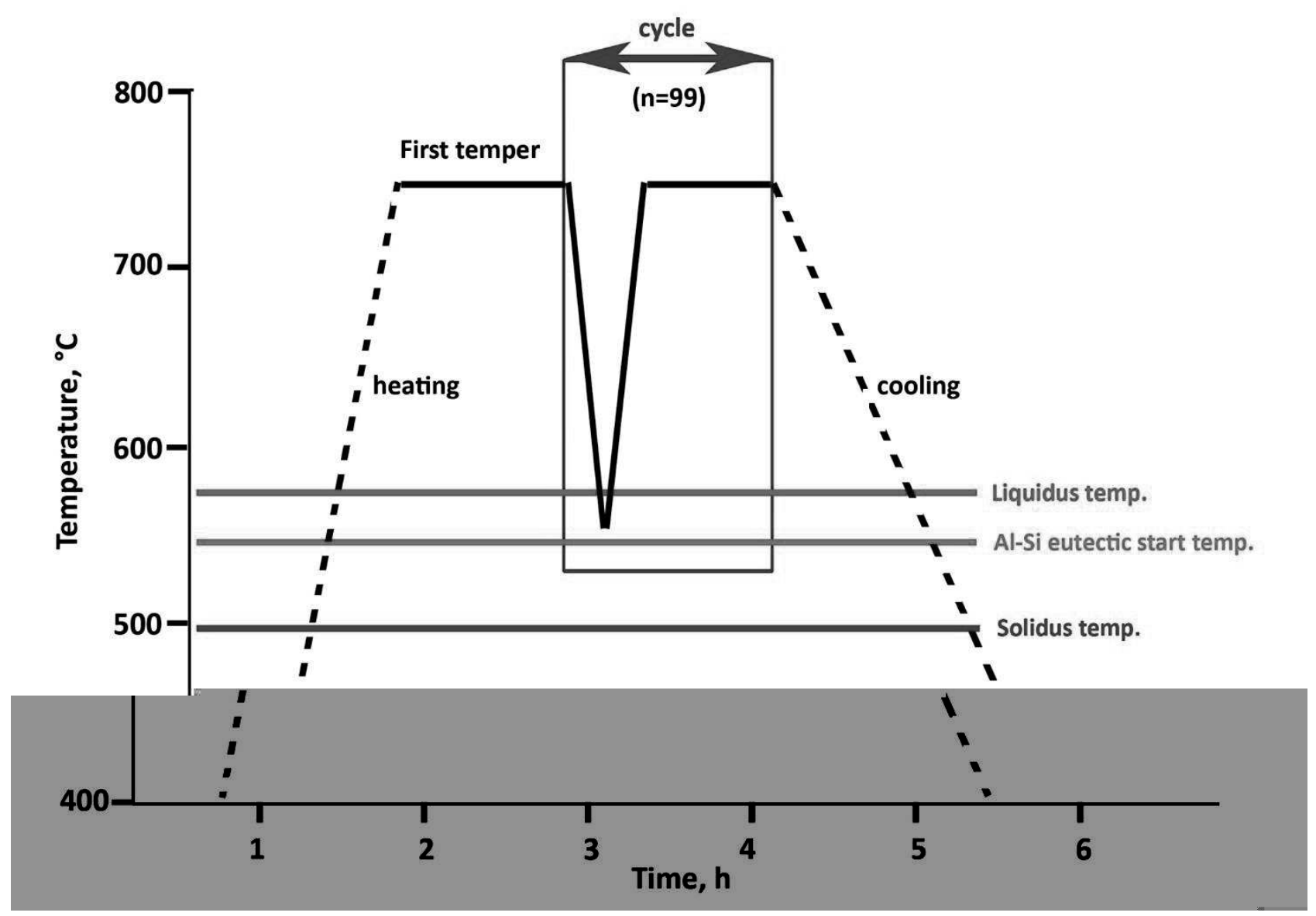

Fig. 2 Scheme of cyclic regime of thermal exposure of the AlSi8Cu2Fe alloy

Tab. 3 Characteristic ratios of the areas of the melt communicating with the surrounding atmosphere to its volume $A / V$, $\mathrm{cm}^{-1}$

\begin{tabular}{|c|c|c|c|}
\hline \multicolumn{2}{|c|}{ Cyclic thermal exposure } & \multicolumn{2}{c|}{ Comparative exposure } \\
\hline Basic state & After $\mathbf{1 0 0}$ cycles & Basic state & After $\mathbf{1 0 0 ~} \mathbf{~}$ \\
\hline 0.16 & 0.20 & 0.16 & 0.18 \\
\hline
\end{tabular}

Metallographic samples were made by conventional metallographic technique. The microstructure of the samples was studied by light microscope Olympus PME 3. Brinell hardness measurements were carried out using a Heckert WPM machine. Hardness of each sample was determined ten times. Mechanical testing of alloys in uniaxial pressure was performed using a universal tensile machine LabTest 5.250SP1 at laboratory temperature.

\section{Results and discussion}

\subsection{Microstructure}

The basic microstructure of all studied alloys was very similar. Due to the high cooling rate during crystallization, it showed a very fine character. The microstructure consists of $\alpha$ - $\mathrm{Al}$ primary dendrites, $\mathrm{Al}-\mathrm{Si}$ euectic and other phases containing $\mathrm{Cu}, \mathrm{Fe}, \mathrm{Mg}$ present in the interdendritic space. Microstructure of base alloy is in the Fig.3. Due to the fine character of the microstructure, the intermediary phases containing the studied elements were distributed uniformly.

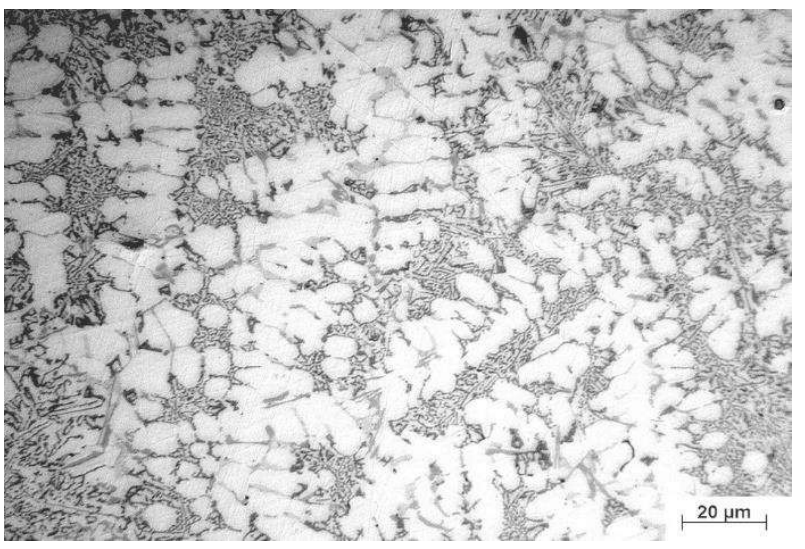

Fig. 3 Microstructure of base AlSi8Cu2Fe alloy

During the thermal exposure, changes in the microstructure of the alloy began to show with increasing number of cycles. An increase in amount of foundry defects was noticeable. These were oxide inclusions and membranes $\left(\mathrm{Al}_{2} \mathrm{O}_{3}\right)$, but also hydrogen porosity. Figs. 4 and 5 are the microstructures of the alloy after $100 \mathrm{~h}$ of cyclic thermal exposure. 


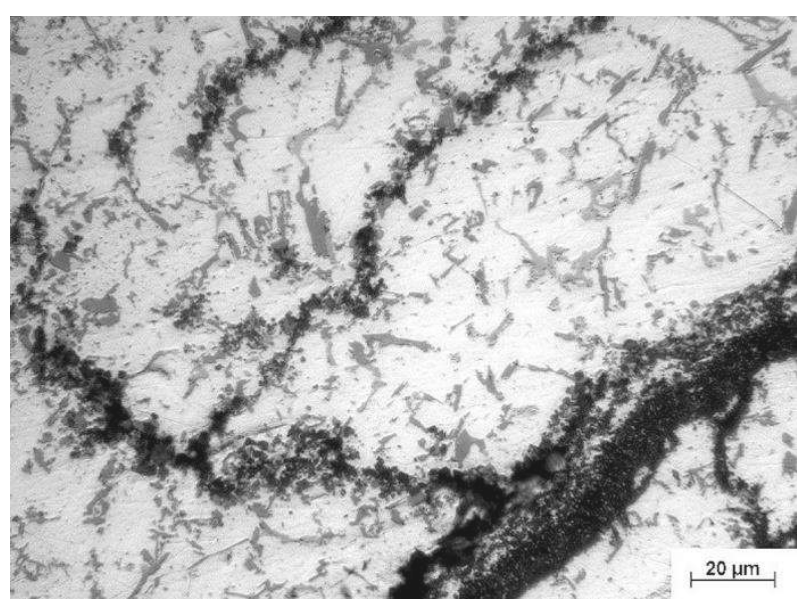

Fig. 4 Microstructure of AlSi8Cu2Fe alloy after 100 cycles of cyclic themal exposure - oxide membranes

Fig. 4 shows a large oxide membrane which significantly disturb the structural homogeneity of the casting, which is also reflected in its mechanical properties. A comparison of the microstructures of this and the base alloy shows a significant coarsenig both $\alpha-\mathrm{Al}$ dendrites and Al-Si eutectic after long-term cyclic exposure. It is evident that the crystallization nuclei in the alloy were affected by thermal cycles.

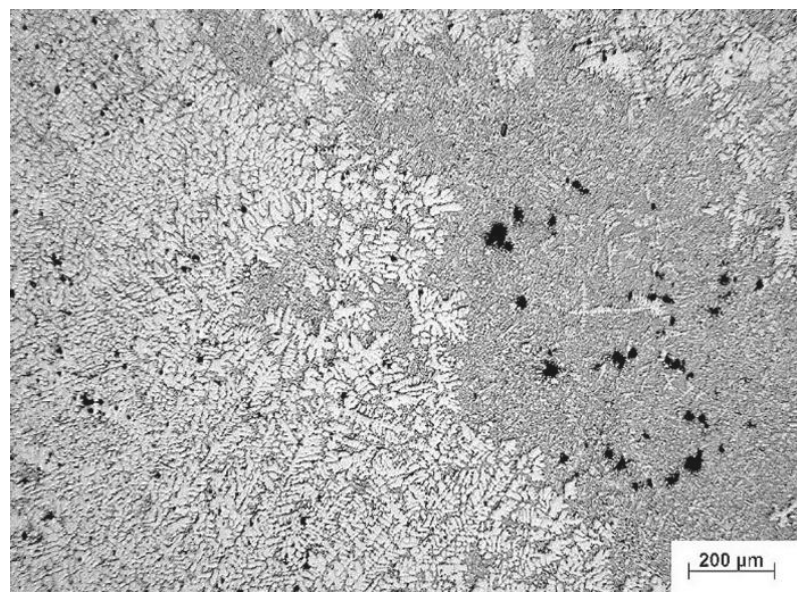

Fig. 5 Microstructure of AlSi8Cu2Fe alloy after 100 cycles of cyclic themal exposure - bydroen porosity

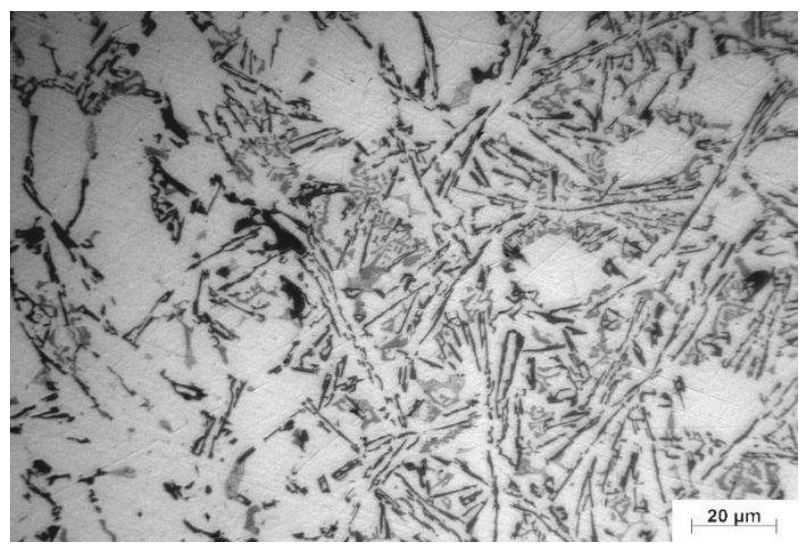

Fig. 6 Microstructure of AlSi8Cu2Fe alloy after 100 hours of themal exposure (reference alloy)
Fig. 5 shows a typical hydrogen porosity in casting, which is also reflected in its mechanical properties. Fig. 6 shows the microstructure of reference alloy after 100 hours of themal exposure. In the case of this alloy, such a significant increase in the portion of foundry defects in the microstructure was not found. However, the microstructure of this alloy is significantly coarser compared to the base alloy.

\subsection{Chemical composition}

Gradual changes in the chemical composition of the alloy also were documented during the cyclic exposure. While the content of some elements ( $\mathrm{Al}, \mathrm{Si}$, $\mathrm{Cu}$ ) practically did not change during the experiment, other elements showed significant changes. The most significant decrease in content during the experiment was found for magnesium (Fig. 7) and, conversely, the most significant increase in content was observed in the case of iron (Fig. 8). A decrease in the content was also found for titanium (Fig. 9), the content of which in the alloy is important for achieving a fine-grained microstructure. For reference alloys that were not subjected to cyclic loading, the changes in element content were always less pronounced.

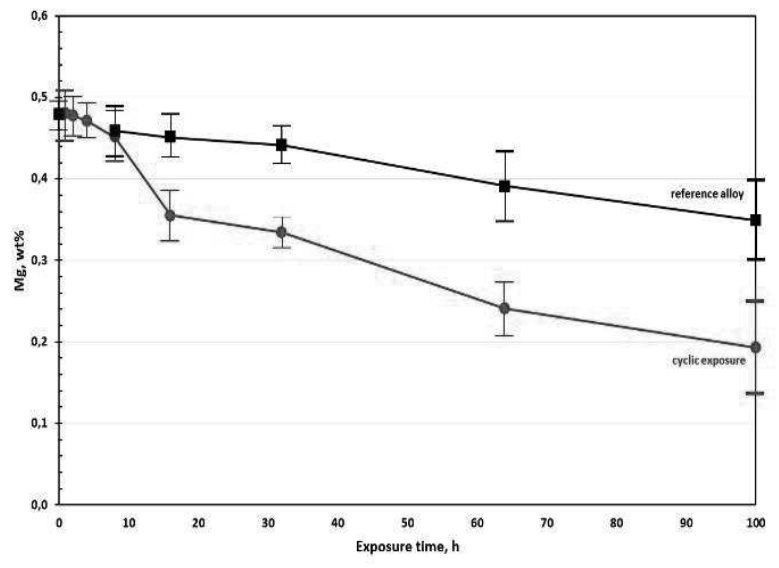

Fig. 7 Dependence of $M g$ content in the casting on the time of thermal exposure

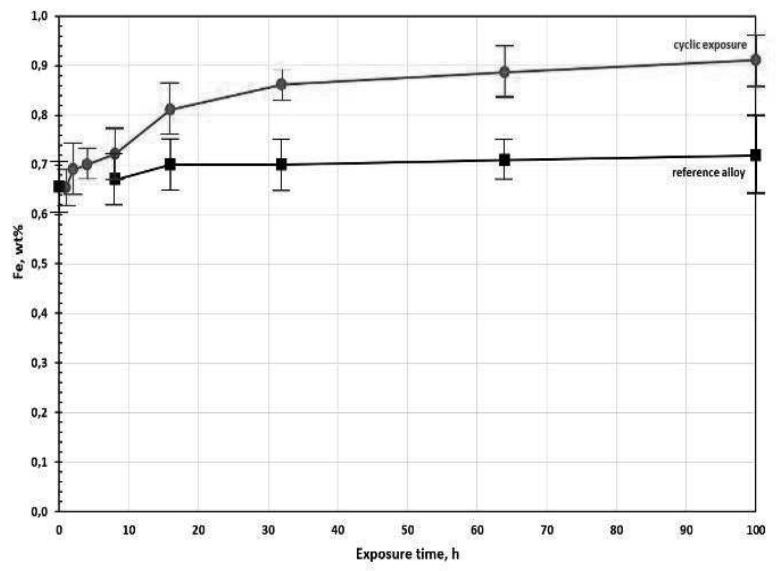

Fig. $\boldsymbol{8}$ Dependence of Fe content in the casting on the time of thermal exposure 


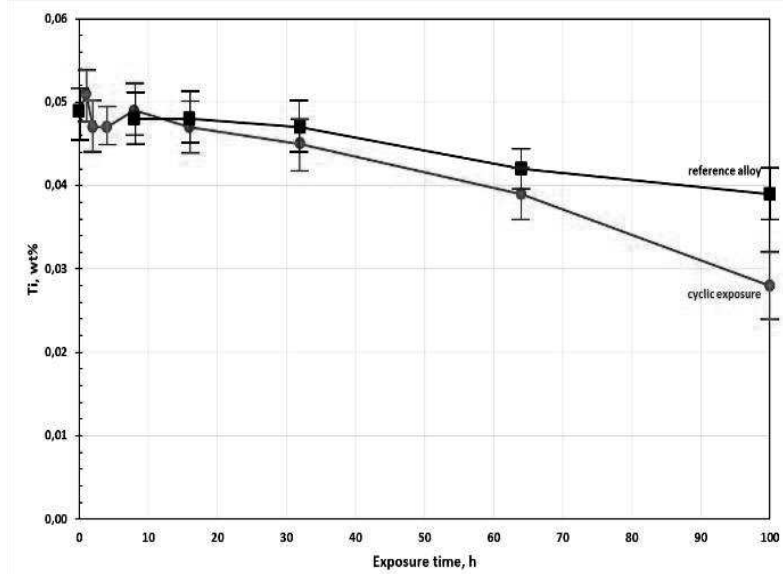

Fig. 9 Dependence of Ti content in the casting on the time of thermal exposure

\subsection{Mechanical properties}

In addition to the microstructure and chemical composition, the continuous changes taking place in the alloy as part of the thermal cyclic exposure necessarily had to affect the mechanical properties as well. This can be seen, for example, in Fig.10, where the Brinell hardness profile is shown. The decrease in hardness values corresponds to the decreasing content of magnesium and titanium in alloy and the coarsening of the microstructure. A decrease in hardness was also observed in the reference samples, but this was not as significant as in the cyclically exposed alloy.

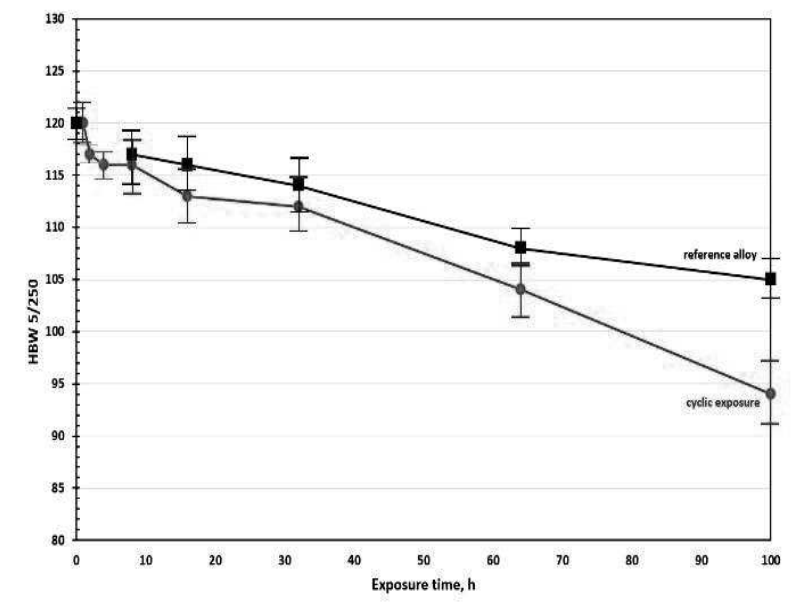

Fig. 10 Dependence of Brinell hardness of casting on the time of thermal exposure

Similar conclusions as for hardness can also be drawn for the results of the uniaxial pressure test. Fig.11 shows the dependence of the yield strength in compression on the number of exposure cycles and in Fig.12 a similar dependence of the compressive strength. In the reference samples, the decrease in mechanical properties was again significantly lower. This is related to the increase in the portion of foundry defects in the microstructure of cyclically exposed alloys.

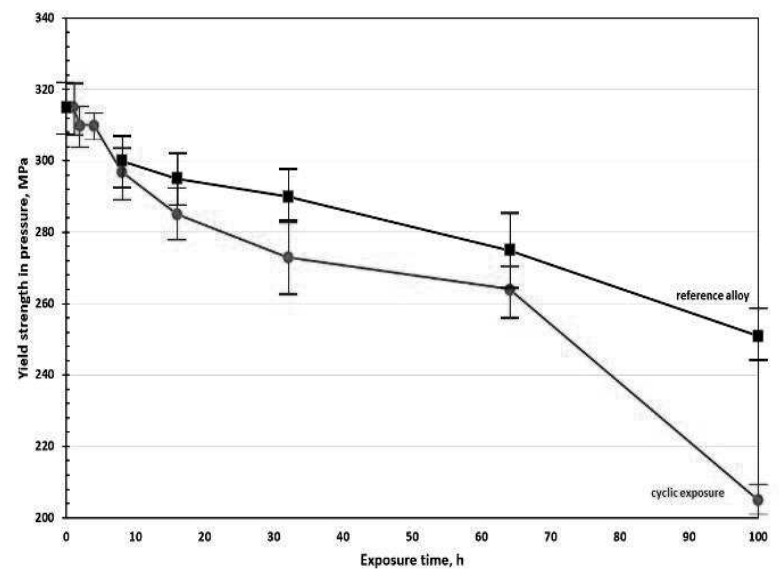

Fig. 11 Dependence of yield strength of casting on the time of thermal exposure

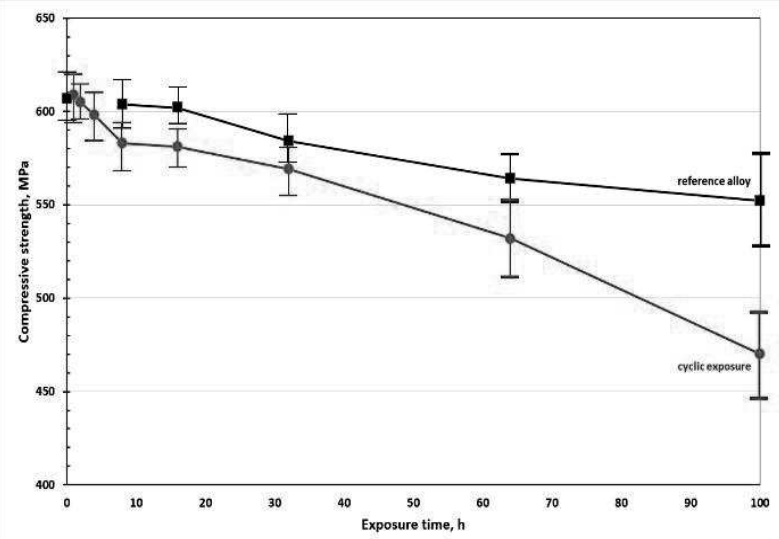

Fig. 12 Dependence of compressive strength of casting on the time of thermal exposure

\section{Conclusion}

It was documented how the microstructure of the AlSi8Cu2Fe alloy was affected by cyclic thermal exposure. With an increasing number of cycles, the microstructure gradually coarsens, and the proportion of foundry defects increases, which correspond with decrease in mechanical properties. With the increasing number of cycles, there are also significant changes in the chemical composition of the melt. Changes in the content of some elements can have important effect on the microstructure and mechanical properties of the alloy. The most significant decrease in content was found for magnesium and titanium. An increase in content during cyclic heat exposure was observed for iron and manganese. In the case of the reference alloys, which were not exposed to cyclic stress, the changes in the properties of the alloy were significantly less pronounced. Cyclic thermal exposure of the alloy poses a risk in the production of castings with reproducible properties. Significant changes in properties did not appear until after 8 cycles. However, with permanently or long-term foundry equipment, cyclic thermal loading can have a very negative effect. 


\section{Acknowledgement}

The presented results were obtained in the frame of the research project of Czech Science Foundation (project No. GA19-08937S) and the specific university research MST No. 21-SVV/2019.

\section{References}

[1] DISPINAR D., CAMPBELL J. (2007). Effect of casting conditions on aluminium metal quality, Journal of Materials Processing Technology, 182, pp. 405-410.

[2] MA, Z., et al. (2010). Parameters controlling the microstructure of $\mathrm{Al}-11 \mathrm{Si}-2.5 \mathrm{Cu}-\mathrm{Mg}$ alloys. Materials \& Design, 2010. 31(2) pp. 902-912.

[3] SOO, V.K., et al. (2018). Sustainable aluminium recycling of end-of-life products: A joining techniques perspective. In: Journal of Cleaner Production, 2018. 178. pp. 119-132.

[4] GRIMAUD, G., PERRY, N., LARATTE, B. (2018). Aluminium cables recycling process: Environmental impacts identification and reduction. In: Resources, Conservation and Recycling, 2018. 135. pp. 150-162.

[5] GROnOstajski, J., A. MAtUszaK, A. (2000). New methods of aluminium and aluminium-alloy chips recycling. In: Journal of Materials Processing Technology, 2000: pp. 34-39.

[6] MICHNA, Š., LUKÁČ, I., OČENÁŠEK, V., KOŘENÝ, R., DRÁPALA, J., SCHNEIDER, H., MIŠKUFOVÁ, A. et. al. (2005). Encyklopedie bliníku, Adin, s. r. o., Prešov, ISBN 80-8904188-4.

[7] DOLEŽAL, J., BRYKSÍ STUNOVÁ, B., KUČERA, V. (2015). Současné poznatky o vlivu doprovodných prvků ve slitinách Al-Si, Slévárenství, Vol. LXIII. 2015. pp.345-348.

[8] ŠERÁK, J., VOJTĚCH, D., REISER M. (2019). Influence of $\mathrm{Sn}, \mathrm{Pb}, \mathrm{Bi}$ and $\mathrm{Sb}$ on the Microstructure and Mechanical Properties of Commercial AlSi8Cu2 Alloy. Manufacturing Technology, Vol. 18, No. 5, 2019, pp. 658 - 691. J.E. Purkyne University in Usti and Labem. Czech Republic.
[9] ŠERÁK, J., VOJTĚCH, D. (2017). Dispersion of Mechanical Properties of Commercial Aluminium Alloys within Their Material Standards. Manufacturing Technology, Vol. 17, No. 5, 2017, pp. 831-837. J.E. Purkyne University in Usti and Labem. Czech Republic.

[10] DJURDJEVIC, M., VICARIO, I. (2013). Description of hypoeutectic $\mathrm{Al}-\mathrm{Si}-\mathrm{Cu}$ alloys based on their known chemical compositions. Revista de Metalurgia 2013, 49, 340-350.

[11] ABDELAZIZ, M., SAMUEL, A., DOTY, H. (2019). Valtierra, S.; Samuel, F., Effect of additives on the microstructure and tensile properties of Al-Si alloys. Journal of Materials Research and Technology 2019, 8.

[12] EFZAN, E., KONG, H.; KOK, C. K. (2013). Review: Effect of Alloying Element on Al-Si Alloys. Advanced Materials Research 2013, 845, 355-359.

[13] LABISZ, K., MARIUSZ, K., DOBRZANSKI, L. (2009). Phases morphology and distribution of the Al-Si-Cu alloy. Journal of Achievements in Materials and Manufacturing Engineering 2009, 37.

[14] BOLIBRUCHOVÁ D., ŽIHALOVÁ M. (2013). Possibilities of iron elimination in aluminum alloys by vanadium. Manufacturing Technology, Vol. 13, No. 3, 2013, pp. 289-296. J.E. Purkyne University in Usti and Labem. Czech Republic.

[15] MARIUSZ, K., KRÓL, M.; MANIARA, R. (2018). Heat Treatment of Al-Si-Cu Alloys. Solid State Phenomena 2018, 275, 15-29.

[16] MOHAMED, A. M. A., SAMUEL, F. (2012). A Review on the Heat Treatment of Al-Si-CuMg Casting Alloys. 2012; pp 55-72.

[17] BALDUCCI, E., CESCHINI, L., MORRI, A., MORRI, A., (2017). EN AW-4032 T6 Piston Alloy After High-Temperature Exposure: Residual Strength and Microstructural Features. Journal of Materials Engineering and Performance, 2017, 26.

[18] RADWAN, B. (2020). Treatment of a Liquid Al-Si Alloy: Quality Control and Comparison of Two Melt Degassing Processes. Dissertation, School of Engineering in Jönköping, 2020. 